\title{
EL PRINCIPIO DE DEVENGADO EN MATERIA TRIBUTARIA
}

\author{
THE ACCRUAL METHOD IN MATTERS OF TAXATION
}

Pedro Choque Ticona Universidad Católica San Pablo, Arequipa, Perú

\section{Resumen:}

El Impuesto a la Renta en Perú reconoce las rentas de tercera categoría (rentas empresariales y los gastos) en base al devengado; sin embargo, la legislación tributaria no ha definido lo que debe entenderse por este principio.

La Superintendencia Nacional de Administración Tributaria, para el reconocimiento de las rentas, emplea en sus pronunciamientos lo establecido en las normas contables (Normas Internacionales de Información Financiera - NIIF). Las resoluciones del Tribunal Fiscal son sustentadas en base a lo establecido en las normas contables (NIIF); pero al momento de definir devengado, no emplean las normas contables sino doctrina jurídica.

En el presente artículo se busca demostrar si es posible emplear las normas contables para definir el devengado en el ámbito tributario.

Palabras clave: Devengado, reconocimiento rentas, reconocimiento gastos

\section{Summary:}

The tax income in Peru recognizes all income which falls in the third category (business income and expenses) based on the (final yield); however, the tax law has not defined what should be understood by this principle. 
The National Superintendency of Tax Administration, for the recognition of earned income, employs in its pronouncements that which is established in accounting standards (International Standards of Financial Reporting - IFRS). The resolutions of the Tax Court are upheld and documented by the IFRS; but when defining earnings, no reference is made to accounting standards, but rather legal doctrine.

The intention of this article is to show whether it is possible to use accounting standards to define (earnings) in the tax field.

Keys words: (Earnings), income recognition, expense recognition

\section{Sumario:}

1. Introducción; 2. Referencia al devengado en las normas tributarias; 3. Referencia al devengado en las normas contables; 4 . La SUNAT y el empleo de normas contables; 5. El Tribunal Fiscal y el devengado; 6. ¿Por qué no utilizar la definición de devengado del Marco Conceptual en materia tributaria?; 7. Conclusiones.

\section{Introducción}

Nadie duda hoy de una vinculación entre la materia tributaria y la contabilidad. Al respecto, el artículo $57^{\circ}$ del T.U.O. de la Ley del Impuesto a la Renta, aprobado por Decreto Supremo Nro. 179-2004-EF, publicado el 8 de diciembre de 2004 en el Diario Oficial El Peruano, establece el reconocimiento de las rentas de tercera categoría en base al devengado. La Ley del Impuesto a la Renta ni su Reglamento han definido lo que debe entenderse por devengado; tanto la Superintendencia Nacional de Administración Tributaria (en adelante SUNAT), así como el Tribunal Fiscal, han utilizado en sus informes y resoluciones, respectivamente, para el reconocimiento de los ingresos y gastos, lo establecido en las normas contables; sin embargo, para definir devengado han recurrido a la doctrina jurídica y no a la contable. Surge entonces la inquietud de conocer la razón del porqué no se ha empleado para la definición de dicho término, lo establecido en la doctrina contable o lo señalado en el Marco Conceptual para la información financiera. El Tribunal Fiscal no considera la definición de devengado del Marco Conceptual para la información financiera, porque no es una norma contable, en tanto que la doctrina contable tampoco es tomada en cuenta, porque no constituye una fuente del derecho tributario. Por su parte los informes de la SUNAT, permiten advertir que no tienen un fundamento claro de la razón del empleo de normas contables para el reconocimiento de los ingresos y gastos, limitándose únicamente a su uso. 
En el presente estudio he procedido a realizar una revisión de los pronunciamientos realizados por la SUNAT que se encuentran publicados en su portal web (http:// www.sunat.gob.pe/legislacion/tributaria/ index.html), en respuesta a las consultas formuladas por las entidades representativas de las actividades económicas, laborales y profesionales; como lo señalan los artículos 93ํy y 94 del T.U.O. del Código Tributario, aprobado por el Decreto Supremo Nro. 1332013-EF, publicado el 22 de junio de 2013, en el Diario Oficial El Peruano:

Artículo 93.- CONSULTAS INSTITUCIONALES Las entidades representativas de las actividades económicas, laborales y profesionales, así como las entidades del Sector Público Nacional, podrán formular consultas motivadas sobre el sentido y alcance de las normas tributarias.

Las consultas que no se ajusten a lo establecido en el párrafo precedente serán devueltas no pudiendo originar respuesta del órgano administrador ni a título informativo.

\section{Artículo 94.- $\quad$ PROCEDIMIENTO DE CONSULTAS}

Las consultas se presentarán por escrito ante el órgano de la Administración Tributaria competente, el mismo que deberá dar respuesta al consultante en un plazo no mayor de noventa (90) días hábiles computados desde el día hábil siguiente a su presentación. La falta de contestación en dicho plazo no implicará la aceptación de los criterios expresados en el escrito de la consulta.

El pronunciamiento que se emita será de obligatorio cumplimiento para los distintos órganos de la Administración Tributaria.

Tratándose de consultas que por su importancia lo amerite, el órgano de la Administración Tributaria emitirá Resolución de Superintendencia o norma de rango similar, respecto del asunto consultado, la misma que será publicada en el Diario Oficial (...).
Tales pronunciamientos del ente administrador del tributo se expresan en Informes, Cartas y Oficios. Dichos pronunciamientos lo efectúan en cumplimiento de lo establecido en el Art. 94ํํㄹ del T.U.O. del Código Tributario, que tiene como efecto su cumplimiento obligatorio por parte de los órganos de la Administración Tributaria, de forma que todos sus funcionarios deberán observar de manera obligatoria lo resuelto por su entidad a través del pronunciamiento emitido. Si bien la posición adoptada por la Administración Tributaria no es obligatoria para el contribuyente, nos ofrece claridad sobre como actuarán sus funcionarios ante un determinado caso.

En cuanto al Tribunal Fiscal, sus pronunciamientos se efectúan a través de resoluciones, que encontramos a disposición en su portal web (http://www. mef.gob.pe/index.php?option=com_con tentEview $=$ section $\mathcal{E} i d=41$ FItemid $=1001$ $45 \mathcal{E}$ lang=es), en las cuales resuelven las controversias entre la Administración Tributaria y los contribuyentes. Dichas resoluciones son de dos tipos: las de observancia obligatoria, que interpretan de modo expreso y con carácter general el sentido de las normas tributarias; debiendo señalarse expresamente en la resolución dicha calidad, además de publicarse en el Diario Oficial El Peruano; estas resoluciones no pueden ser cuestionadas ante el Poder Judicial por la Administración Tributaria, pero los contribuyentes sí pueden hacerlo. Y las otras resoluciones, son aquellas que resuelven un caso en concreto, pero cuya interpretación no tiene alcance general, 
como la jurisprudencia de observancia obligatoria a que se refiere los artículos 102ㅜㅡ y 154 del T.U.O. del Código Tributario; por ello, estas resoluciones pueden ser cuestionadas ante el Poder Judicial, tanto por la Administración Tributaria como por el contribuyente.

\section{Referencia al devengado en las normas tributarias}

La Ley del Impuesto a la Renta, establece en su Art. 57:

A los efectos de esta Ley, el ejercicio gravable comienza el 1 de enero de cada año y finaliza el 31 de diciembre, debiendo coincidir en todos los casos el ejercicio comercial con el ejercicio gravable, sin excepción.

Las rentas se imputarán al ejercicio gravable de acuerdo con las siguientes normas:

a) Las rentas de la tercera categoría se considerarán producidas en el ejercicio comercial en que se devenguen.

En el caso de Instrumentos Financieros Derivados, las rentas y pérdidas se considerarán devengadas en el ejercicio en que ocurra cualquiera de los siguientes hechos:

1. Entrega física del elemento subyacente.

2. Liquidación en efectivo.

3. Cierre de posiciones.

4. Abandono de la opción en la fecha en que la opción expira, sin ejercerla.

5. Cesión de la posición contractual.

6. Fecha fijada en el contrato de swap financiero para la realización del intercambio periódico de flujos financieros.

Para el caso de Instrumentos Financieros Derivados celebrados con fines de intermediación financiera por las empresas del Sistema Financiero reguladas por la Ley General del Sistema Financiero y del Sistema de Seguros y Orgánica de la Superintendencia de Banca y Seguros, Ley № 26702, las rentas y pérdidas se imputarán de acuerdo con lo dispuesto en el numeral 2) del inciso d) del artículo 5-A de la presente Ley.

Las rentas de las personas jurídicas se considerarán del ejercicio gravable en que cierra su ejercicio comercial. De igual forma, las rentas provenientes de empresas unipersonales serán imputadas por el propietario al ejercicio gravable en el que cierra el ejercicio comercial.

b) Las rentas de primera categoría se imputarán al ejercicio gravable en que se devenguen.

c) Las rentas de fuente extranjera que obtengan los contribuyentes domiciliados en el país provenientes de la explotación de un negocio o empresa en el exterior, se imputarán al ejercicio gravable en que se devenguen.

d) Las demás rentas se imputarán al ejercicio gravable en que se perciban.

Las normas establecidas en el segundo párrafo de esteartículo serán de aplicación para la imputación de los gastos.

Excepcionalmente, en aquellos casos en que debido a razones ajenas al contribuyente no hubiera sido posible conocer un gasto de la tercera categoría oportunamente y siempre que la Superintendencia Nacional de Administración Tributaria - SUNAT compruebe que su imputación en el ejercicio en que se conozca no implica la obtención de algún beneficio fiscal, se podrá aceptar su deducción en dicho ejercicio, en la medida que dichos gastos sean provisionados contablemente y pagados íntegramente antes de su cierre.

La Ley reconoce en varios casos que la imputación de las rentasy gastos se efectuará en base al ejercicio en que devenguen; sin embargo, no se ha ocupado de definir lo que debe entenderse por devengado, ni los criterios que deben tenerse en cuenta.

En la Ley del Impuesto a la Renta se presentan otras referencias al devengado

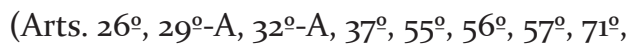


$73^{\circ}-\mathrm{B}, 84^{\circ}, 85^{\circ}, 88^{\circ}$, y de las disposiciones finales transitorias: la segunda, trigésimo quinta, trigésimo sexta, y cuadragésimo cuarta), pero en ninguno de ellos se le define, lo mismo ocurre con el Reglamento de la Ley; por su parte, en el resto de normas tributarias tampoco encontramos la definición ni criterios que permitan colegir una definición.

\section{Referencia al devengado en las normas contables}

En las normas contables no encontramos una definición en sí de lo que es devengado, sino la oportunidad del reconocimiento de los elementos de los estados financieros, como en qué momento se reconoce un ingreso cuando se vende un bien (párrafo 14 de la NIC 18 Ingresos, en adelante NIC 18) o cuando se presta un servicio (párrafo 20 de la NIC 18); pero sí se cuenta con una definición en el Marco conceptual para la información financiera (modificado en setiembre de 2010), el cual establece "los conceptos que subyacen en la preparación y presentación de los estados financieros para usuarios externos" (IFRS FOUNDATION, 2012). Dicho Marco Conceptual aclara en los párrafos segundo y tercero del Propósito y valor normativo:

Este Marco Conceptual no es una NIIF, y por tanto no define normas para ninguna cuestión particular de medida o información a revelar. Ningún contenido de este Marco Conceptual deroga cualquier NIIF específica. El Consejo reconoce que en un limitado número de casos puede haber un conflicto entre el Marco Conceptual y una NIIF. En esos casos en que exista conflicto, los requerimientos de la NIIF prevalecerán sobre los del Marco Conceptual. No obstante, como el Consejo se guiará por el Marco Conceptual al desarrollar futuras NIIF y en su revisión de las existentes, el número de casos de conflicto entre el Marco Conceptual y las NIIF disminuirá con el tiempo. (IFRS FOUNDATION, 2012)

El propio Marco Conceptual aclara que no tiene valor de norma contable lo que él establece, sino que el Marco Conceptual constituye una guía de desarrollo de las futuras NIIF. En el párrafo OB17 define al devengado, en los términos siguientes:

La contabilidad de acumulación (o devengo) describe los efectos de las transacciones y otros sucesos y circunstancias sobre los recursos económicos y los derechos de los acreedores de la entidad que informa en los periodos en que esos efectos tienen lugar, incluso si los cobros y pagos resultantes se producen en un periodo diferente. Esto es importante porque la información sobre los recursos económicos y los derechos de los acreedores de la entidad que informa y sus cambios durante un periodo proporciona una mejor base para evaluar el rendimiento pasado y futuro de la entidad que la información únicamente sobre cobros y pagos del periodo. (IFRS FOUNDATION, 2012).

La versión original (antes de la modificación de setiembre de 2010) del Marco Conceptual, denominado Marco conceptual para la preparación y presentación de los estados financieros corresponde a 1989 (publicado en julio del mismo año y adoptado por el IASB en abril de 2001); el cual contiene una definición del devengado en el párrafo 22:

Con el fin de cumplir sus objetivos, los estados financieros se preparan sobre la base de la acumulación o del devengo contable. Según esta base, los efectos de las transacciones y demás sucesos se reconocen cuando ocurren (y no cuando se recibe o paga dinero $\mathrm{u}$ otro equivalente al efectivo), asimismo se 
registran en los libros contables y se informa sobre ellos en los estados financieros de los periodos con los cuales se relacionan. Los estados financieros elaborados sobre la base de acumulación o del devengo contable informan a los usuarios no sólo de las transacciones pasadas que suponen cobros o pagos de dinero, sino también de las obligaciones de pago en el futuro y de los recursos que representan efectivo a cobrar en el futuro. Por todo lo anterior, tales estados suministran el tipo de información, acerca de las transacciones y otros sucesos pasados, que resulta más útil a los usuarios al tomar decisiones económicas. (IACS, 2000).

Además, encontramos el devengo en los siguientes párrafos del Marco Conceptual vigente:

4.48 Los procedimientos adoptados normalmente en la práctica para reconocer ingresos, por ejemplo el requerimiento de que los mismos deban estar acumulados (o devengados), son aplicaciones de las condiciones para el reconocimiento fijadas en este Marco Conceptual. Generalmente, tales procedimientos van dirigidos a restringir el reconocimiento como ingresos sólo a aquellas partidas que, pudiendo ser medidas con fiabilidad, posean un grado de certidumbre suficiente.

4.49 Se reconoce un gasto en el estado de resultados cuando ha surgido un decremento en los beneficios económicos futuros, relacionado con un decremento en los activos o un incremento en los pasivos, y además el gasto puede medirse con fiabilidad. En definitiva, esto significa que tal reconocimiento del gasto ocurre simultáneamente con el reconocimiento de incrementos en las obligaciones o decrementos en los activos (por ejemplo, la acumulación o el devengo de salarios, o bien la depreciación del equipo). (IFRS FOUNDATION, 2012).

Como es de observarse, el devengo sólo es referido en el Marco Conceptual en tres (3) párrafos: $\mathrm{OB}_{17}, 4.48$ y 4.49, definiéndolo en el primero de los citados. De lo señalado en dicho párrafo queda claro que el devengo se distancia del concepto de percepción, porque no considera en absoluto si en el hecho económico se ha producido el cobro o pago. De haberse realizado un pago o cobro, ello no deberá tomarse en cuenta a efecto de establecer si se produjo el devengo.

La parte inicial del párrafo $\mathrm{OB} 17$ del Marco Conceptual refiere que el devengo contable es similar o lo asimila a acumulado, a sumar, juntar, añadir; y no lo relaciona específicamente con los ingresos o gastos sino que se refiere a los recursos económicos y los derechos de la entidad que informa, de lo cual puede colegirse que el devengo contable debe considerarse a efecto del reconocimiento de los distintos elementos de los estados financieros y no únicamente de los ingresos, ganancias y gastos. En ese sentido, si determinado hecho económico reúne las condiciones para el reconocimiento como un elemento de los estados financieros (activo, pasivo, patrimonio, ingresos, gastos), entonces se podrá señalar que se ha “devengado”.

De la revisión de las Normas Internacionales de Información Financiera (NIIF), que se encuentran compuestas por las Normas Internacionales de Contabilidad (NIC), las interpretaciones de las NIC (CNIC), las Normas Internacionales de Información Financiera (NIIF) y sus interpretaciones (CINIIF), he observado que ninguna de ellas contiene una definición de devengado pero sí se refieren a dicho término como se muestra en el siguiente cuadro: 


\section{Cuadro Nro. 1:}

Referencias de devengado en las normas

\begin{tabular}{|c|c|c|c|c|c|c|c|c|c|}
\hline \multirow{2}{*}{\begin{tabular}{|l|} 
Tipo \\
NIC \\
\end{tabular}} & \multirow{2}{*}{\begin{tabular}{|c|} 
Nro. \\
1
\end{tabular}} & \multicolumn{7}{|c|}{ Párrafo } & \multirow{2}{*}{\begin{tabular}{|c|} 
Total \\
3
\end{tabular}} \\
\hline & & 27 & 28 & 70 & & & & & \\
\hline & 7 & 18 & 36 & & & & & & 2 \\
\hline & 12 & 7 & 8 & & & & & & 2 \\
\hline & 17 & 4 & 40 & 41 & 47 & & 48 & & 5 \\
\hline & 18 & 30 & 32 & & & & & & 2 \\
\hline & 19 & 10 & 38 & 44 & 50 & & 68 & & 5 \\
\hline & 20 & 16 & & & & & & & 1 \\
\hline & 28 & 17 & & & & & & & 1 \\
\hline & 32 & $97 \mathrm{C}$ & GA17 & & & & & & 2 \\
\hline & 33 & 21 & & & & & & & 1 \\
\hline & 37 & II & & & & & & & 1 \\
\hline & 39 & 81 & GA6 & & & & & & 2 \\
\hline SIC & \multicolumn{3}{|c|}{ Ninguna } & & & & & & o \\
\hline \multirow[t]{4}{*}{ NIIF } & 1 & D18 & & & & & & & 1 \\
\hline & 7 & 20 & & & & & & & 1 \\
\hline & 9 & 3.2 .5 & B3.1.5 & B3.2.17 & B4.1.13 & B4.3.8 & B5.1.1 & B5.1.2 & 7 \\
\hline & 13 & $\mathrm{D}_{23}$ & $\mathrm{D}_{3} 6$ & Dio5 & & & & & 3 \\
\hline CINIIF & \multicolumn{3}{|c|}{ Ninguna } & & & & & & o \\
\hline
\end{tabular}

Fuente: Normas contables

Elaboración: Propia

\section{La SUNAT y el empleo de normas contables}

Luis Durán Rojo y Marco Mejía Acosta (2011), realizan un interesante trabajo de la revisión de los pronunciamientos emitidos por la SUNAT, del empleo de las normas contables. En dicho estudio demuestran que dicha Administración Tributaria al absolver las consultas formuladas por los contribuyentes, hace uso de las normas contables para señalar el tratamiento tributario de determinadas operaciones, es decir, que es tomado en cuenta en la interpretación que efectúa.
Las normas contables consideradas por esta entidad en los informes, cartas y oficios emitidos en respuesta a las consultas formuladas por los contribuyentes son tomadas en cuenta -como lo señalan Durán Rojo y Mejía Acosta-, en base a lo siguiente:

\subsection{Derivación genérica a normas contables}

La SUNAT recurre a normas contables sin señalar la razón o motivo de recurrir a ellas y no a otras, vale decir, no señala que recurre a ellas al constituir normas jurídicas ni que sean principio de Derecho ni menos como doctrina jurídica. Un ejemplo de ello se encuentra en el Informe Nro. 149-2010-SUNAT (emitido el 25 de octubre de 2010), en el cual establece: "Los ajustes por valor de actualización constante a las cuotas de un contrato de arrendamiento financiero deberán computarse en la base imponible del Impuesto a la Renta en el ejercicio de su devengo, para lo cual deberá tenerse en cuenta las normas contables sobre la materia y los términos pactados en el contrato respectivo".

4.2. Uso de normas contables como fuente interpretativa sin sustentar la razón de ello

En el Informe Nro. 048-2010-SUNAT (emitido el 29 de abril de 2010), la SUNAT se pronuncia señalando:

En relación con el otorgamiento de las denominadas "garantías extendidas" en la venta de bienes, conferidas por una empresa comercializadora a un consumidor final en adición a la garantía otorgada por el fabricante del bien: 
1. El monto que por concepto de garantía extendida debe pagar el comprador forma parte de la base imponible del IGV correspondiente a la venta del bien garantizado.

2. El ingreso porgarantía extendida obtenido por las empresas comercializadoras se considera devengado durante el período de cobertura del contrato.

3. Los gastos relacionados con la garantía extendida se devengarán en el ejercicio o período en que se realiza o se presta el servicio a fin de atender las obligaciones que cubre dicha garantía.

En el caso citado, la SUNAT considera que corresponde recurrir a los principios contables, y los diferencia de la doctrina jurídica, pues en dicho informe cita también a Enrique Reig, considerándolo como doctrina jurídica, pero las citas de los principios contables no los asimila a doctrina jurídica.

\subsection{Uso de normas contables como fuente interpretativa al amparo de la Norma IX del Título Preliminar del Código Tributario}

En el Informe Nro. 124-2010-SUNAT (31 de agosto de 2010), la SUNAT señala:

Para fines del Impuesto a la Renta, dentro de la expresión "edificaciones y construcciones" deben entenderse comprendidas las edificaciones propiamente dichas y toda construcción, obra de arquitectura o ingeniería que tienen como características su fijeza y permanencia, ésta última asociada a una vida útil relativamente extensa, similar a la que corresponde a un edificio, no se destinan para la venta en el curso normal de las operaciones de una entidad, y se utilizan en el proceso de producción o comercialización o para uso administrativo y que están sujetas a depreciación, excepto terrenos.

Formarán parte de las edificaciones y construcciones todos los bienes y materiales que sean necesarios para su puesta en funcionamiento, uso o aprovechamiento económico, así como los aditamentos de carácter permanente que tengan una vida útil relativamente larga como la obra.

En el presente informe la SUNAT señala que al no existir en la Ley del Impuesto a la Renta una definición de los términos “construcción" y "edificación", resulta necesario recurrir a sus significaciones usuales, así como suplementariamente a otros dispositivos legales, de conformidad con la Norma IX del Título Preliminar del Texto Único Ordenado del Código Tributario.

Luego realiza una revisión de la NIC ${ }_{16}$ Inmuebles, Maquinaria y Equipo, señalando que los edificios y otras construcciones comprenden activos que la entidad utiliza para la producción o suministro de bienes y servicios. Posteriormente, realiza una cita del Manual del Contador de W. A. Paton.

Como puede notarse, la referencia a la Norma IX del Título Preliminar del Código Tributario, es por considerar las normas contables como normas jurídicas o principios del Derecho Tributario, del Derecho Administrativo o del Derecho en general; sin embargo, en el informe no establece en cuál de éstas se encuentran las normas contables.

\subsection{Uso de normas contables como fuente normativa}

El Informe Nro. 146-2010-SUNAT (20 de octubre de 2010), la SUNAT se pronuncia en el siguiente sentido: 
1. El derecho de llave calificado como activo intangible no forma parte del fondo de comercio o goodwill. Para efecto de la determinación del Impuesto a la Renta, la deducción del precio pagado por un derecho de llave está condicionada a que se pruebe que se trata de un intangible de duración limitada.

2. Tratándose de un derecho de llave que aflora con ocasión de una adquisición estructurada a partir de dos operaciones: a) adquisición del cien por ciento de las acciones de una empresa y, posteriormente, b) absorción de dicha empresa por la adquirente de las acciones; para efecto del Impuesto a la Renta, dicho derecho de llave sólo puede amortizarse por la empresa adquirente a partir de la entrada en vigencia de la fusión, siempre que sea identificable como un activo de duración limitada.

En este caso la SUNAT considera en la parte inicial del Informe, en la parte referida a Base legal, la cita siguiente: "Norma Internacional de Contabilidad (NIC) N. 38, cuya aplicación fue oficializada por la Resolución del Consejo Normativo N. 342005-EF/93.01, publicada el 2.3.2005”. De lo cual, se colige que la SUNAT considera que las normas contables constituyen fuente normativa y, en tanto, estaría aplicando lo establecido en la Norma III del Título Preliminar del Código Tributario y no la Norma IX.

De lo señalado podemos advertir que la SUNAT emplea las normas contables pero sin una base consistente, porque no llega a precisar bajo qué ámbito las emplea, si es como normas jurídicas o principios del Derecho Tributario, del Derecho Administrativo o del Derecho en general o doctrina jurídica.

\section{El Tribunal Fiscal y el devengado}

Antes de referirme a la importancia de la jurisprudencia del Tribunal Fiscal, revisemos brevemente qué debe entenderse por jurisprudencia. Para Jaime Lara, (2006), la jurisprudencia es el conjunto de resoluciones concordantes y coincidentes sobre una misma materia que establece criterios vinculantes de alcance general.

De acuerdo con Marcial Rubio (2009), la jurisprudencia en sentido lato son las resoluciones que los magistrados judiciales emiten en ejercicio de sus atribuciones jurisdiccionales, para solucionar los conflictos a ellos sometidos, que se suscitan entre los individuos o entre estos y la sociedad. Mientras que en sentido estricto se refiere propiamente a las resoluciones que emite el máximo tribunal, pero no a las resoluciones de los tribunales y juzgados inferiores a él. En sentido clásico, puede entenderse que la jurisprudencia proviene de los tribunales de justicia; sin embargo, también se tiene la jurisprudencia administrativa, que es aquella emitida por la administración pública, para solucionar problemas jurídicos que caen bajo su competencia.

El Código Tributario establece en la Norma III de su Título Preliminar, qué constituye una de las fuentes del Derecho Tributario a la jurisprudencia. Al referirse a que constituye una fuente formal de Derecho Tributario, lo hace indicando que constituye un vehículo a través del cual se pueden insertar normas jurídicas en el sistema, generando diversos efectos en el mismo. Sin embargo, más que 
una fuente formal de derecho constituye una fuente real, pues los jueces al resolver las controversias de manera uniforme y coincidente establecen criterios vinculantes de alcance general (2006).

\subsection{Sistemas jurisprudenciales}

Jaime Lara (2006), señala que existen dos sistemas de jurisprudencia vinculante: el de la unidad científica y el sistema de la obligatoriedad instituida. A continuación desarrollaremos ambos sistemas.

\subsubsection{Sistema de la unidad científica}

Mediante el sistema de la unidad científica, el criterio jurisprudencial se forma a lo largo de los años por acumulación de decisiones individuales que tienen similar pronunciamiento, aportando todas ellas en la construcción de la doctrina jurisprudencial, que permita dar respuesta a situaciones no previstas. Los argumentos reiterados vienen a conformar lo que se denomina línea jurisprudencial, reiterada jurisprudencia o jurisprudencia uniforme.

\subsubsection{Sistema de la obligatoriedad instituida}

Este sistema corresponde a aquél donde su criterio vinculante se origina en circunstancias temporales y personales, de manera que se conoce el tribunal $u$ órgano que lo instituyó, la oportunidad de su emisión y el caso en el cual se produjo. A diferencia del anterior sistema, éste se produjo en un momento determinado.
Dentro de este sistema se presentan dos formas de establecer el precedente: el del precedente jurisprudencial y el de la jurisprudencia de observancia obligatoria.

\subsubsection{El precedente jurisprudencial}

Es aquél que se establece mediante sentencias emitidas por los tribunales superiores, como los del Tribunal Constitucional, en los cuales establecen criterios vinculantes de alcance general, los que tienen carácter de obligatorio cumplimiento de parte de las instancias inferiores y obviamente de los justiciables.

El criterio vinculante no se encuentra formalmente formulado ni señalado como si fuera una norma jurídica sino que debe ser extraído de la resolución mediante un proceso inductivo, considerando que corresponde a un caso particular y la decisión fue pronunciada en dicho sentido; pero que contiene un principio aplicado que es de alcance general, para aplicarse en los demás casos similares.

Los precedentes se mantendrán vigentes en tanto no se haya producido una modificación legislativa o un cambio de criterio del mismo tribunal; ello por cuanto la naturaleza de la jurisprudencia suele ser dinámica y cambiante y sea proclive a un mayor desarrollo y precisión por pronunciamientos posteriores. 


\subsubsection{La jurisprudencia de observancia obligatoria}

En este sistema se otorga calificación expresa de que la resolución contiene criterio vinculante, tanto para el propio tribunal como para las instancias inferiores.

Para el establecimiento de la jurisprudencia de observancia obligatoria se cuenta con un procedimiento establecido para su calificación, aprobación y sanción. Esta calificación solo está establecida para casos excepcionales, disponiéndose en su mayoría la publicación en el Diario Oficial El Peruano.

Existen dos clases de jurisprudencia de observancia obligatoria, primero, aquella que califica que la resolución constituye jurisprudencia de observancia obligatoria, sin que toda ella contenga un único criterio, como sucedía en el caso del Tribunal Fiscal hasta el año 2001; y segundo, cuando además de calificar la resolución como jurisprudencia de observancia obligatoria, señala cuál es el párrafo que establece el criterio vinculante. Ello se ha establecido en los Arts. $102^{\circ}$ y $154^{\circ}$ del Código Tributario.

El Tribunal Fiscal emite resoluciones con la calidad Observancia Obligatoria y por tanto vinculantes; así también emite resoluciones que resultan aplicables a cada caso en particular, pero cuyo reiterado pronunciamiento adquiere la calidad de vinculante.

\subsection{Pronunciamientos del Tribunal Fiscal sobre devengado}

A continuación los resultados de la revisión efectuada a las Resoluciones del Tribunal Fiscal, emitidas desde 1996, en las cuales se ha considerado el principio de devengado en la resolución de sus casos; dicha revisión se ha efectuado con el propósito de analizar si el Tribunal Fiscal considera las normas contables en la resolución de los casos de naturaleza tributaria -pues sólo puede pronunciarse el Tribunal en materia tributaria-, y de haberlas considerado, bajo qué forma: como norma jurídica, como doctrina jurídica, como principio de Derecho Tributario, etc.

De las resoluciones del Tribunal Fiscal emitidas desde el año 1996 hasta el 2011, se han encontrado 152 en las cuales existe referencia al deven gado. En las resoluciones existen diversas referencias a las normas contables, pero dado que la materia de investigación es el devengado, sólo se consideró las resoluciones referidas a este principio.

Luego de la identificación de las resoluciones y análisis de las mismas, se ha encontrado los siguientes resultados: 
Cuadro Nro. 2:

Referencias de devengado en las resoluciones del Tribunal Fiscal

\begin{tabular}{|c|c|c|c|c|c|c|}
\hline \multirow{2}{*}{ Año } & \multirow{2}{*}{ Cant. } & \multicolumn{3}{|c|}{$\begin{array}{c}\text { Fundamenta uso } \\
\text { de norma contable }\end{array}$} & \multicolumn{2}{c|}{$\begin{array}{c}\text { Señala norma } \\
\text { contable }\end{array}$} \\
\cline { 3 - 7 } & & Sí & No & $\begin{array}{c}\text { Referida a } \\
\text { otro tributo }\end{array}$ & Sí & No \\
\hline 1996 & 2 & 0 & 1 & 1 & 0 & 1 \\
1997 & 5 & 0 & 5 & 1 & 0 & 5 \\
1998 & 9 & 0 & 8 & 1 & 0 & 9 \\
1999 & 3 & 0 & 3 & 0 & 1 & 2 \\
2000 & 7 & 0 & 6 & 0 & 0 & 6 \\
2001 & 16 & 0 & 16 & 0 & 6 & 10 \\
2002 & 11 & 0 & 11 & 0 & 1 & 10 \\
2003 & 12 & 0 & 12 & 1 & 6 & 6 \\
2004 & 15 & 0 & 15 & 0 & 10 & 5 \\
2005 & 8 & 0 & 8 & 0 & 6 & 2 \\
2006 & 11 & 0 & 11 & 0 & 8 & 3 \\
2007 & 12 & 0 & 11 & 1 & 10 & 2 \\
2008 & 7 & 0 & 7 & 0 & 7 & 0 \\
2009 & 12 & 0 & 12 & 0 & 9 & 3 \\
2010 & 12 & 0 & 12 & 1 & 10 & 2 \\
2011 & 10 & 0 & 10 & 0 & 3 & 7 \\
\hline Total & 152 & & & & & \\
\hline
\end{tabular}

Fuente: Resoluciones del Tribunal Fiscal en su portal Elaboración: Propia

Las resoluciones emitidas por el Tribunal Fiscal no fundamentan la razón del empleo de las normas contables. No mencionan si se consideró la norma contable como una norma jurídica, como doctrina jurídica, principio de Derecho Tributario o principio de Derecho Administrativo.

También se encontró la referencia a otros tributos, como en el caso del Impuesto General a las Ventas (IGV). Pero que no tiene mayor efecto por cuanto dicho tributo no considera para su determinación el concepto de "devengado".

El empleo del devengado en las resoluciones del Tribunal Fiscal se efectuó en casos referidos a:

- Descuentos

- Intereses
- Exportaciones

- Devoluciones de pagos en exceso

- Ingresos cobrados por anticipado

- Comisiones

- Deducción de gastos

- Reconocimiento de ingresos

- Compensación de saldo a favor del exportador (SFE)

- Operaciones gravadas con el IGV

- Liquidación provisional

- Venta de minerales

- Emisión de facturas

- Ingresos por minería

- Devoluciones

- Reconocimiento de costos e ingresos;

- Gastos en alquiler de vehículos

- Intereses de créditos vencidos en entidades financieras

- Derecho de llave goodwill

- Alquiler de volquetes

- Valorizaciones de servicios

- Intereses por contribuciones financieras

- Pólizas de seguros

- Notas de abono

- Indemnizaciones por lucro cesante

- Bienes entregados en consignación

- Depreciaciones

- Intereses moratorios

- Cuotas devengadas en periodos de gracia

- Intereses presuntos

- Provisiones

- Gastos de ejercicios anteriores

\subsection{Autores considerados por el Tribunal} Fiscal en sus Resoluciones

En las resoluciones del Tribunal Fiscal revisadas se ha advertido la referencia a 
Enrique Jorge Reig y a Juan Roque García Mullín, mas no a otros autores.

Según Reig (1998), "el ingreso devengado es, entonces, todo aquel sobre el cual se ha adquirido el derecho de percibirlo por haberse producido los hechos necesarios para que se genere. Correlativamente en cuanto a los gastos, se devengan cuando se causan los hechos en función de los cuales, terceros adquieren derecho al cobro de la prestación que los origina”.

Agrega más adelante que el concepto de devengado tiene las siguientes características:

1. Requiere que se haya producido los hechos sustanciales generadores del ingreso o del gasto.

2. Requiere que el derecho al ingreso o compromiso de gasto no esté sujeto a condición que pueda hacerlo inexistente.

3. No requiere actual exigibilidad o determinación, ni fijación de término preciso para el pago; puede ser obligación a plazo y de monto no determinado. (REIG, 1998).

Por su parte, García Mullín refiriéndose al devengado, señala:

En el sistema de lo "devengado", también llamado "causado", se atiende únicamente al momento en que nace el derecho al cobro, aunque no se haya hecho efectivo. Dicho de otro modo, la sola existencia de un título o derecho a percibir la renta, independientemente de que sea exigible o no, lleva a considerarla como devengada, y por ende imputable a ese ejercicio.

Como contrapartida, tratándose de gastos, el principio de lo devengado se aplica considerándolos imputables (deducibles) cuando nace la obligación de pagarlos, aunque no se hayan pagado, ni sean exigibles. (GARCÍA MULLÍN, 1978).
El Tribunal Fiscal, al fundamentar sus resoluciones, considera en varios casos lo señalado por estos autores; llama la atención que el Tribunal no haya considerado la definición del devengado contenido en el Marco Conceptual para la información financiera, teniendo en cuenta la proximidad existente entre la Contabilidad y el aspecto tributario, y en especial, cuando en muchas resoluciones se fundamenta con citas de las Normas Internacionales de Contabilidad (NIC).

\section{6. ¿Por qué no utilizar la definición del devengado del Marco Conceptual en materia tributaria?}

Considerando que la Ley del Impuesto a la Renta ni su Reglamento establecen una definición o concepto de devengado, es necesario que revisemos cuáles son las fuentes del Derecho Tributario que reconoce el Código Tributario.

\subsection{Fuentes formales de Derecho Tributario}

La fuente formal de Derecho es aquel procedimiento a través del cual se producen, válidamente, normasjurídicasqueadquieren el rasgo de obligatoriedad propio del Derechoy, por lo tanto, las características de ser impuestas legítimamente a las personas mediante los instrumentos de coacción del Estado (RUBIO CORREA, 2009).

Entonces una fuente formal de Derecho tributario será el procedimiento válido mediante el cual se logra una norma tributaria que puede ser impuesta por 
el Estado, empleando la coacción de ser necesario.

El Código Tributario vigente (Decreto Supremo Nro. 133-2013-EF), establece en la Norma III del Título Preliminar, las fuentes de Derecho Tributario, señalando:
a) Las disposiciones constitucionales;
b) Los tratados internacionales aprobados por el Congreso y ratificados por el Presidente de la República;
c) Las leyes tributarias y las normas de rango equivalente;
d) Las leyes orgánicas o especiales que norman la creación de tributos regionales o municipales;
e) Los decretos supremos y las normas reglamentarias;
f) La jurisprudencia;
g) Las resoluciones de carácter general emitidas por la Administración Tributaria; $y$,
h) La doctrina jurídica.

Al respecto, se pueden plantear dos cuestionamientos al considerar como fuente a la jurisprudencia y a la doctrina jurídica.

La jurisprudencia es el conjunto de resoluciones concordantes y coincidentes sobre una misma materia que establecen criterios vinculantes de alcance general (2006). Al respecto, surge el cuestionamiento de considerar a la jurisprudencia como un medio para lograr una norma tributaria válida, o en realidad es la interpretación que considera un Tribunal como válida, posición a la que me adhiero; porque no crea una nueva norma, sino que simplemente establece una posición en la interpretación de una norma.
Por otra parte, la doctrina jurídica es el conjunto de escritos aportados al Derecho a lo largo de toda su historia, por autores dedicados a describir, explicar, sistematizar, criticar y aportar soluciones dentro del mundo jurídico (2009). La doctrina jurídica tampoco crea normas tributarias sino que su finalidad es de ser un gran ordenador y expositor del sistema jurídico legislado. Su función de describir le permite exponer sistemáticamente grupos de normas diseminados en diversas épocas y con diversas ubicaciones jerárquicas dentro del Derecho nacional (2009).

Nótese que la referencia en la Norma III del Título Preliminar del Código Tributario, es a la doctrina jurídica y noa la doctrina contable, por tanto, esta última no constituiría una fuente de Derecho Tributario. De manera tal, que el Tribunal Fiscal hace bien en no referirse a la doctrina contable por cuanto ella no constituye una fuente reconocida para el Derecho Tributario.

\subsection{Las normas contables no son normas jurídicas}

De acuerdo con Aníbal Torres (2008), o la norma o regla jurídica es un esquema o programa de conducta que disciplina la convivencia social, en un lugar y momento determinados, mediante la prescripción de derecho y deberes, cuya observancia puede ser impuesta coactivamente.

Por su parte Marcial Rubio (2009), desde un carácter lógico jurídico, sostiene que la norma jurídica es un mandato de que a cierto supuesto debe seguir, lógico-jurídicamente, 
una consecuencia, estando tal mandato respaldado por la fuerza del Estado para el caso de su eventual incumplimiento.

Para que se encuentre respaldado por la fuerza del Estado dicha norma debe ser publicada en el Diario Oficial El Peruano, conforme lo establece el Art. 109ํㅜ de la Constitución Política del Perú. Tal artículo señala: "La ley es obligatoria desde el día siguiente de su publicación en el diario oficial, salvo disposición contraria de la misma ley que posterga su vigencia en todo o en parte".

Dicha definición contiene tres elementos que conforman su estructura interna: el supuesto (hipótesis que genera la consecuencia), la consecuencia (es el efecto generado por el supuesto cuando se produce en la realidad), y el nexo lógico jurídico (elemento lógico vinculante).

Las Normas Internacionales de Información Financiera no tienen la calidad de normas jurídicas por cuanto no han sido publicadas en el Diario Oficial El Peruano, conforme lo exige la Constitución Política en su Art. 109․․ La regulación efectuada en el Art. 223ำ de la Nueva Ley General de Sociedades, aprobada por Ley Nro. 26887 y publicada el 9 de diciembre de 1997, establece que "Los estados financieros se preparan y presentan de conformidad con las disposiciones legales sobre la materia y con principios de contabilidad generalmente aceptados en el país"; y la aclaración realzada por el Consejo Normativo de Contabilidad en el Art. 1o de la Resolución Nro. 013-98-EF/93.01, publicada el 23 de julio de 1998, en la que precisa que los Principios de Contabilidad Generalmente
Aceptados comprender, substancialmente, a las Normas Internacionales de Contabilidad (NIC), oficializadas mediante Resoluciones del Consejo Normativo de Contabilidad; no es suficiente para que las NIC alcancen la categoría de normas jurídicas, al carecer de publicación en el Diario Oficial El Peruano.

\subsection{Interpretación de las normas tributarias}

El Derecho no utiliza un lenguaje propio sino que toma el lenguaje común y es elaborado mediante él. El Derecho es compartido por especialistas y legos, por lo que es fácil suponer que existirán problemas de comprensión y comunicación. De acuerdo con Enrique Haba (HABA, 1979), existen tres planos de análisis del lenguaje, que son: el sintáctico, el semántico y el pragmático. El plano sintáctico se refiere a las reglas de organización de la expresión lingüística, con ello me refiero a la gramática española. Téngase presente que el Derecho, a diferencia de otras disciplinas (la matemática, la lógica, etc.), no generará una gramática propia. El plano semántico se encuentra referido al significado de los vocablos. La etimología nos ayuda a encontrar el significado de los términos, de manera que en algunos casos su significado será uno común de las palabras y en otros le asignará uno propio; por ello se da muchas veces que la misma palabra sea empleada en sentido común y en otra, en un sentido jurídico distinto. El plano pragmático es la manera como lo entiende normalmente la sociedad. Y ello se da cuando se suman la gramática y la semántica, para buscar el significado del contenido de la norma jurídica. 
Armando Zolezzi (2003), considera que interpretar una norma es determinar el sentido y alcance de la misma; pero que no cualquiera con una simple lectura puede determinar el sentido y alcance del texto legal; aun la más clara requiere ser interpretada.

Él distingue que, según el operador del Derecho, podrán presentarse diversas clases de interpretación:

\section{- Interpretación legislativa}

Conocida como auténtica, y es aquella que tiene carácter obligatorio, confundiéndose con la ley interpretada, y formando con ella un solo cuerpo. Tiene un carácter universal (erga omnes), siendo su alcance el mismo que la ley interpretada.

Nuestra Constitución la establece en el numeral 1 del Art. 102º, que establece: "Dar leyes y resoluciones legislativas, así como interpretar, modificar o derogar los existentes".

\section{- Interpretación administrativa}

Es aquella que efectúa el Presidente de la República al reglamentar las leyes. Dicha atribución se encuentra contenida en el numeral 8 del Art. 118 - de la Constitución, que establece: "Ejercer la potestad de reglamentar las leyes sin transgredirlas ni desnaturalizarlas; $y$, dentro de tales límites, dictar decretos y resoluciones".

Otro ejemplo lo tenemos en el Art. 93ํㅡㄴ del Código Tributario, que establece:
"Las entidades representativas de las actividades económicas, laborales y profesionales, así como las entidades del Sector Público Nacional, podrán formular consultas motivadas sobre el sentido y alcance de las normas tributarias". En el cual obliga al órgano administrador del tributo a realizar una interpretación administrativa.

También encontramos en el Art. 154ำ del Código Tributario, otro caso, cuando establece que: "Las resoluciones del Tribunal Fiscal que interpreten de modo expreso y con carácter general el sentido de normas tributarias, así como las emitidas en virtud del Artículo 102, constituirán jurisprudencia de observancia obligatoria para los órganos de la Administración Tributaria, mientras dicha interpretación no sea modificada por el mismo Tribunal, por vía reglamentaria o por ley. En este caso, en la resolución correspondiente el Tribunal Fiscal señalará que constituye jurisprudencia de observancia obligatoria y dispondrá la publicación de su texto en el Diario Oficial".

\section{- Interpretación judicial}

Correspondea la realizada por los jueces al aplicar la ley a un caso concreto, buscando el sentido y alcance de la norma.

\section{- Interpretación doctrinaria}

Es la que corresponde a los juristas, y tiene un carácter orientador al legislador cuando legisla, al juez cuando aplica la ley, 
o al funcionario cuando aplica la ley. Estas posiciones de los juristas se encuentran en los libros, ensayos, artículos, conferencias, etc., en los que participan.

El primer párrafo de la Norma VIII del Título Preliminar del Código Tributario, señala: "Al aplicar las normas tributarias podrá usarse todos los métodos de interpretación admitidos por el Derecho”. Por su parte, la Norma IX del mismo cuerpo normativo establece: "En lo no previsto por este Código o en otras normas tributarias podrán aplicarse normas distintas a las tributarias siempre que no se les opongan ni las desnaturalicen. Supletoriamente se aplicarán los Principios del Derecho Tributario, o en su defecto, los Principios del Derecho Administrativo y los Principios Generales del Derecho"; de forma tal que si en la Ley del Impuesto a la Renta existieran vacíos o deficiencias, el intérprete podrá recurrir supletoriamente a los principios del Derecho Tributario, luego a los del Derecho Administrativo, y después a los Principios Generales del Derecho.

Se puede advertir que la norma establece un orden de empleo señalando en primer lugar las normas tributarias, y sólo en caso que no se encuentre una regulación en ella, se podrán aplicar normas distintas a las tributarias, en tanto no sean opuestas. Y en defecto de éstas, podrán emplearse los principios, pero no todos los principios sino primero los del ámbito tributario, luego del Derecho Administrativo y finalmente, los Principios Generales del Derecho; obsérvese que no se ha referido en ningún momento a principios contables sino únicamente a los principio vinculados al Derecho; por tanto, al no ser reconocidas las Normas Internacionales de Contabilidad (hoy Normas Internacionales de Información Financiera), como principios del Derecho, no pueden emplearse de forma supletoria a las normas tributarias.

\section{Conclusiones}

7.1. El Impuesto a la Renta establece que las rentas de tercera categoría se considerarán en el ejercicio comercial en que se devenguen, y los gastos siguen el mismo criterio. Sin embargo, dicha Ley ni su Reglamento definieron lo que debe entenderse por devengado.

7.2. El Marco Conceptual para la información financiera no señala que el devengo resulta aplicable únicamente a los ingresos, ganancias y gastos sino, se desprende de él, que debe tomarse en cuenta en el reconocimiento de los distintos elementos de los estados financieros.

7.3. El devengo para las Normas Internacionales de Información Financiera (NIIF) va más allá de referirse sólo a ingresos y gastos, incluye también el reconocimiento de activos, pasivos y patrimonio, en tanto satisfagan las definiciones y criterios del Marco Conceptual.

7.4. La SUNAT considera las normas contables en la interpretación de las normas tributarias, sin señalar de forma clara y uniforme la razón de recurrir a ellas. 
7.5. El Tribunal Fiscal emplea en sus resoluciones normas contables, sin indicar un fundamento sólido de su empleo; porque no menciona si las considera como norma jurídica, doctrina jurídica, principio de Derecho Tributario o principio de Derecho Administrativo.

7.6. La definición de devengado empleado por el Tribunal Fiscal en sus resoluciones no proviene de normas contables sino de la doctrina jurídico-tributaria (Enrique Jorge Reig y Juan Roque García Mullín). El Tribunal Fiscal no fundamenta en sus resoluciones la razón del empleo de la doctrina jurídica.

7.7. En materia tributaria, no debe emplearse la definición de devengado del Marco Conceptual de la información financiera ni de lo establecido en una Norma Internacional de Información Financiera (NIIF) por no constituir una norma jurídica, ni principio del Derecho Tributario, del Derecho Administrativo o Principio General del Derecho.

\section{Referencias}

Durán Rojo, Luis Y Mejía Acosta, Marco (2011). Las NIIF y la interpretación de las normas tributarias por SUNAT, en “Revista Enfoque Contable”, Nro. 1, Lima: Asesoramiento y Análisis Laborales S.A.C. - AELE.
García Mullín, Juan (1978). "Manual de Impuesto a la Renta”. Buenos Aires: Organización de los Estados Americanos - Programa del Sector Público - CIET.

IASC (200o). "Normas Internacionales de Contabilidad 200o". Lima: Federación de Colegios de Contadores Públicos del Perú.

Ifrs Foundation (2012). "Normas Internacionales de Información Financiera - NIIF Español 2012". Parte A, Londres: IFRS Foundation Publications Department.

Haba, Enrique (1979). Apuntes sobre el lenguaje jurídico: de la lengua común a la letra de las leyes. San José de Costa Rica: En Revista de Ciencias Jurídicas, Nro. 37.

Lara Márquez, Jaime (2006). La jurisprudencia del Tribunal Fiscal. En AA.VV.: "Temas de Derecho Tributario y de Derecho Público - Libro Homenaje a Armando Zolezzi Möller”. Lima: Palestra Editores S.A.C.

Reig, Enrique (1998). "Impuesto a las ganancias". 9na. Ed. Córdoba: Ediciones Macchi.

Rubio Correa, Marcial (2009). "El sistema jurídico - Introducción al Derecho”. 10 Ed., Lima: Fondo Editorial de la Pontificia Universidad Católica del Perú.

Torres V., Aníbal (2008). "Introducción al Derecho - Teoría General del Derecho". 3ra. Ed., Lima: Importadora y Distribuidora Editorial Moreno S.A.

Zolessi M., Armando (2003). Prólogo al Libro "Interpretación de las normas tributarias" de Marcial Rubio Correa. Lima: ARA Editores E.I.R.L. 